\title{
WEAR RESISTANCE OPTIMIZATION OF COPPER, LEAD, TIN ALLOYS
}

\author{
K. N. Abushgair \\ Mechanical Engineering Department, Faculty of Engineering Technology, \\ Al-balqa' Applied University, Amman, Jordan \\ P.O.Box 15008, 11134 Amman, Jordan; Email: khaleel45@yahoo.com
}

(Received March 19 , 2006 Accepted April 17, 2006)

\begin{abstract}
In the present study different copper-lead-tin alloys were prepared by casting. A wear test device was designed and manufactured to study the wear resistance of these alloys under different values of contact forces and sliding velocities. The data obtained from the wear test is modeled by the Adaptive Nearo Fuzzy Inference System (ANFIS) to predict an alloy of the highest wear resistance. Comparison between predicted an experimental wear results show good agreement. There are more than one combination of the considered copper alloy that show optimum resistance to wear, namely an alloy composed of $(\mathrm{Cu}=$ $75 \%, \mathrm{~Pb}=5 \%, \mathrm{Sn}=20 \%)$, and that composed of $(\mathrm{Cu}=85 \%, \mathrm{~Pb}=$ $5 \%, S n=10 \%)$.It was also found that the increase of lead decreases the wear resistance, while percentage of tin above $7 \%$ increases the wear resistance of these copper base alloys. This is attributed to the change in the micro-structure of the tested alloys.
\end{abstract}

\section{INTRODUCTION}

Wear is defined as a progressive loss or displacement of material from a surface as a result of relative motion at the interface. Friction is the most important factor effecting wear, but there is no simple direct relationship between friction and wear. For a given metallic couple, low friction will generally result in low wear, and the converse is also true. There are other factors effecting wear, such as, lubrication, surface texture, surface hardness, etc. $[1,2]$.

There are many physical wear mechanisms, such as, adhesion, abrasion, fatigue, erosion, fretting, impact wear, corrosive and oxidation. These representative mechanisms serve to illustrate that there is more than one distinct mechanism for wear, and that wear sensitive to parameters such as wear forces and velocities, [3].

\section{Sliding Bearing Material}

A sliding bearing (plain bearing) is a machine element designed to transmit loads or reaction forces to a shaft that rotates relative to the bearing. $[3,4,5]$.

In the present work copper base alloys have been studied since these alloys have long been used for bearings because of their combination of moderate to high strength, corrosion resistance, and either wear resistance or self lubrication properties. 


\section{Fuzzy Modeling}

Fuzzy set theory provides a framework for modeling vague systems since it simplifies the understanding of such systems. This approach allows for the treatment of uncertainty due to fuzziness, and for the increased understanding of complex systems $[6,7]$.

Since wear resistance is highly dynamic system that have many variables affecting the desired results, the fuzzy approach becomes especially valuable in developing models for such system. A fuzzy set model is used to get the optimal composition of the copper base alloys.

\section{Present Work}

The main goal of the present study is an attempt to study the wear resistance of sliding bearing material to get the best alloys with the optimal wear resistance under different contact forces and sliding velocities.

In this work samples of different compositions of copper-lead-tin alloys were tested for wear resistance under different values of contact forces and sliding velocities.

A wear testing device was constructed and used. The data obtained from these tests were modeled using ANFIS to predict the copper-lead-tin percentages give the optimal wear resistance [8].

\section{Materials}

\section{MATERIALS AND EQUIPMENT}

Commercial copper, lead and tin were received in granular forms from the local Jordanian market. Different compositions of these metals in the alloys were prepared, each from four workpieces were casted. Workpieces for wear test were designed as wheels in each six holes were drilled, one hole at the center and the other five at a certain diameter between the center and the periphery as shown in Fig. 1. Each workpiece could be used for five tests by holding it in the wear test device through the centered hole and one peripheral hole.

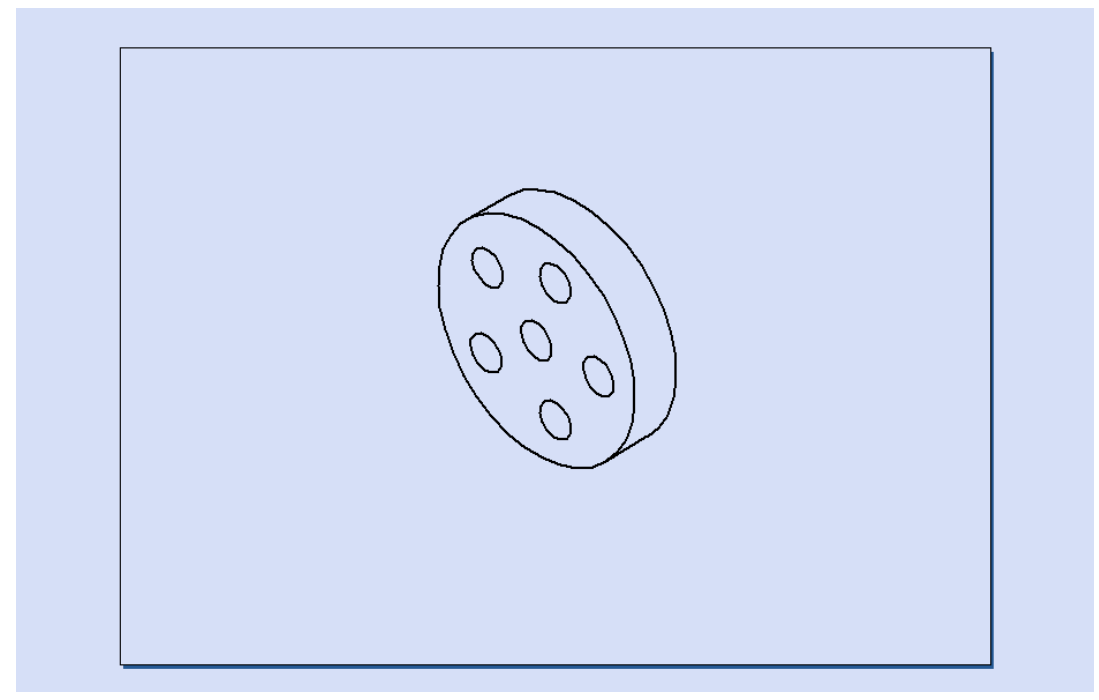

Fig. 1: Schematic diagram of workpiece. 


\section{Casting Process}

After calculating the weight for the three different metal in each alloy, a special die was design and manufactured from mild steel. A furnace of type VickstarEngeanal M\#12 and a graphite crucibles were used. The casting process starts by melting the copper $\left(\mathrm{Tm}=1083{ }^{\circ} \mathrm{C}\right)$ at $1200{ }^{\circ} \mathrm{C}$. then mixed with tin and lead, and poured into the die. After cooling, workpiece of $43 \mathrm{~mm}$ diameter and $10 \mathrm{~mm}$ thickness were finally turned to have specimens of $38 \mathrm{~mm}$ diameter and $7.8 \mathrm{~mm}$ thickness.

\section{Wear Test Device Specifications}

The wear test was carried out using a lathe machine ( Colchester Master 2500 ). A simple wear testing device was designed and manufactured to study the wear resistance. The wear test device contains two parts, one induces the wear force and the other holds the workpiece. First part can be mounted on the head of the lathe machine while the second part is a hard disk attached to the spindle of the lathe. The disk was received with a hardness (51 HRC) and it was ground before each test in order to remove any traces and scratches. Figure 2 shows the wear test device which consists of: the shank (1) that is bolted to the casing (3), which includes the sliding tool stem (4) to carry the pre-calibrated spring $(2)$ by which wear force $(\mathrm{Pw})$ can be measured. Figure 3 shows the calibration curve for the spring.

\section{EXPEREMENTAL DETAILS}

\section{Wear Experiments}

A typical experimental set up for a wear testing process is shown in Fig. 4. Each workpiece ( wheel ) was fixed at the stem (adapter) with two bolts and then workpiece holding device moved so that the surface of the workpiece touch the surface of the disk. The tool post was fixed, then the required contact force was developed, then the lathe spindle is turned on with the required velocity. The range of all the forces and velocities used throughout the experiments are listed in Table 1. The duration for each test was kept constant at one minute.

The test surface of the workpiece and the rotating disk were cleaned thoroughly with alcohol before starting the wear test process. Cleaning with alcohol was continued when ever it was thought to be needed during the test, in order to prevent any hard particles that may be formed during the process from entering between the rolling and the surface of the metal.

\section{Measurements of Material Loss}

The initial weight for all the workpiece was taken and reported. The wear test was carried out and the final weight at the end of each test becomes the initial weight for the next test and so on each workpiece can be used for five tests. The difference between the initial and final weights for each test represents the weight loss $(\Delta \mathrm{W})$. Special digital balance (Metller AE200) with precision of $0.0001 \mathrm{Kg}$ was used. 


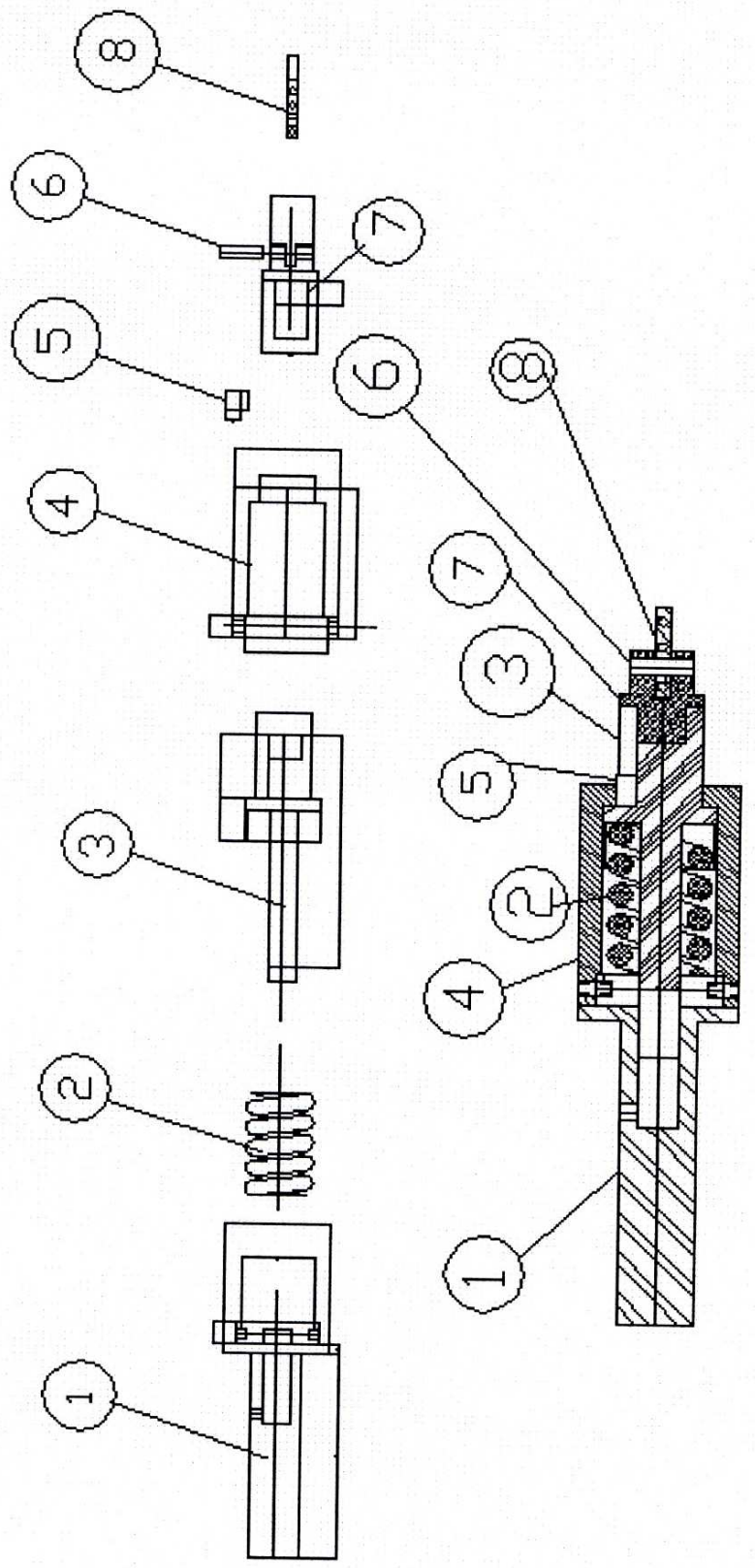

Fig. 2: Detail and assembly drawing of part one for the wear testing device: (1) shank, (2) calibrated spring, (3) sliding tool stem (adapter), (4) Casing, (5) Key, (6) Pin, (7),(8) Workpiece holder. 


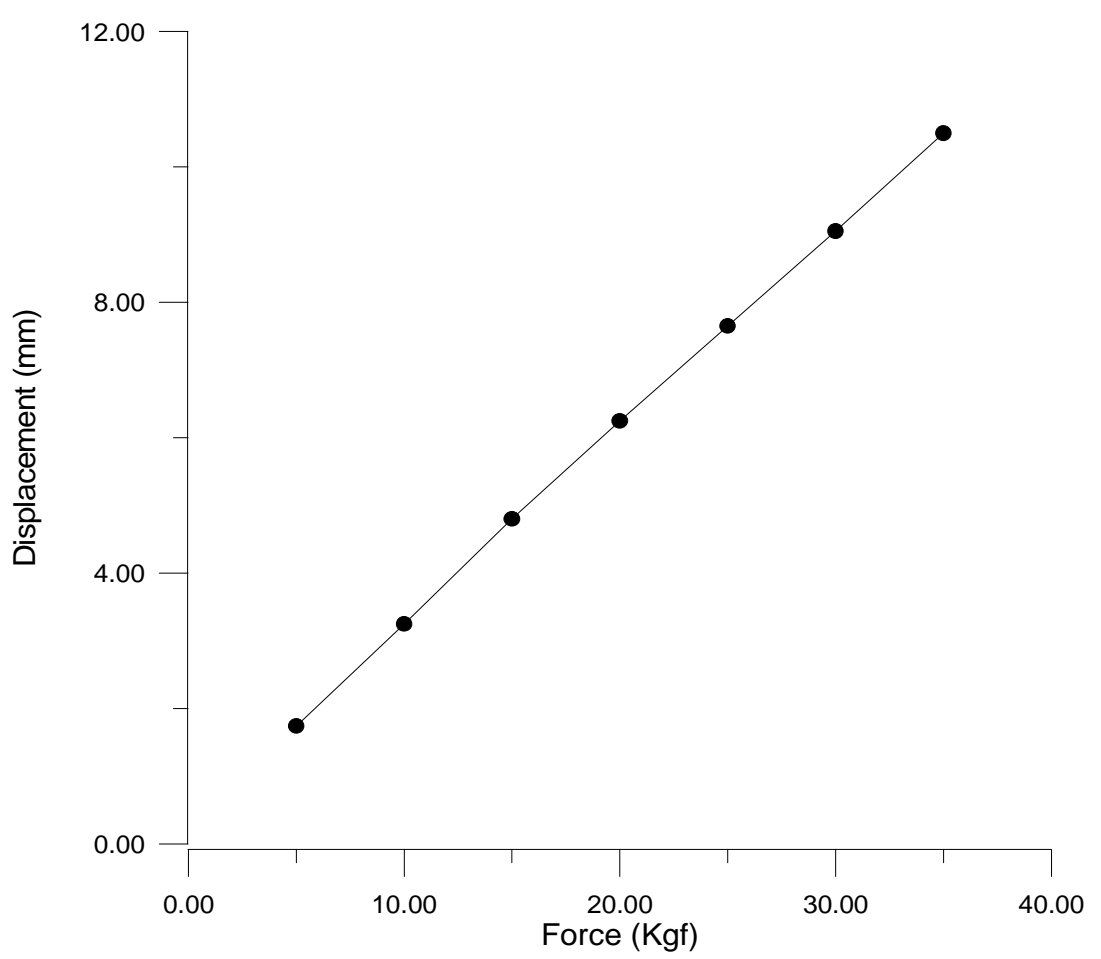

Fig. 3: Calibration curve for the wear test device spring.

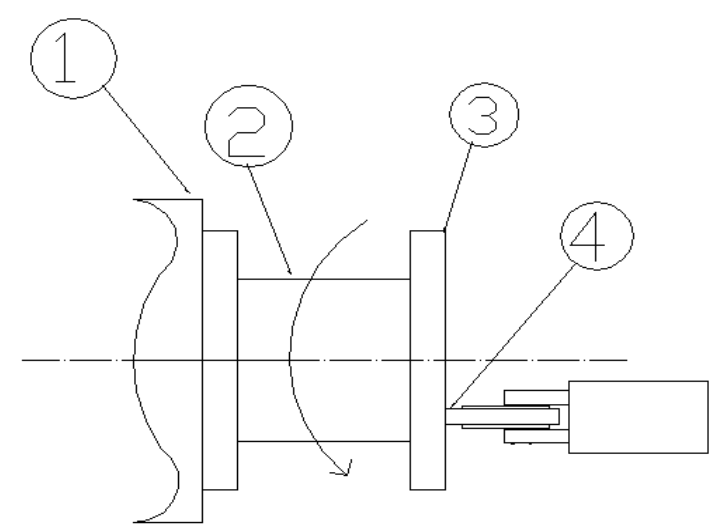

Fig. 4: Schematic representation of the wear testing device set-up:

(1) Head stock (2) Spindle. (3) Disk. (4) Workpiece.

Table 1: Wear parameters.

\begin{tabular}{|l|c|}
\hline Contact force $\mathrm{P}_{\mathrm{W}},(\mathrm{Kgf})$ & $5,7.5,10,12.5$ \\
\hline Contact velocity $\mathrm{V}_{\mathrm{w}},(\mathrm{m} / \mathrm{min})$ & $170,127,94,70,54$ \\
\hline
\end{tabular}




\section{RESULTS AND DISCUSSION}

\section{Effect of Copper Percentage in Copper-Lead-Tin Alloys on Wear}

Figure 5 shows the effect of copper percentages on weight losses at different forces and velocities. The lead percentage is kept constant at a certain value of $5 \%$, while the tin percentage is changed according to the change of copper percentages. These figures show that there are different copper percentages for minimum weight losses. This means that there are more than percentage of copper gives optimal wear resistance. It can be noted that $(\mathrm{Cu}=85 \%)$, and $(\mathrm{Cu}=75 \%$, ) can be considered as the optimum copper percentages which can be used to obtain minimum weight losses.

\section{Effect of Lead Percentage in Copper-Lead-Tin Alloys on Wear}

The effect of lead percentage on weight loss for the considered alloy, where copper is kept constant at 70\%, and the tin percentage varies with the change in lead percentages as shown in Fig. 6. Each curve has been taken for certain velocities and applied forces. It is noticed that the weight loss is increasing by increasing the lead percentages and decreasing the tin percentages in each alloy. It can be seen from these figures that the increase in weight loss is slightly increased up to about $11 \% \mathrm{~Pb}$ then there is a rapid increase up to $25 \% \mathrm{~Pb}$. This is due to the fact that the lead increase in the alloy will cause a decrease in the hardness of the alloy. This can be explained as the presence of lead in the alloy as pure and discrete phase, because its solid solubility in the matrix is nil. So interrupt the continuity of the matrix and render it softer. Strength and hardness are degraded because of the interruption of continuity for the copper-tin alloy matrix by soft and weak lead. Thus through judicious control of tin content, lead content, an entire family of bearing alloys can be evolved to suit a wide variety of bearing applications, and also with different mechanical properties for different working conditions.

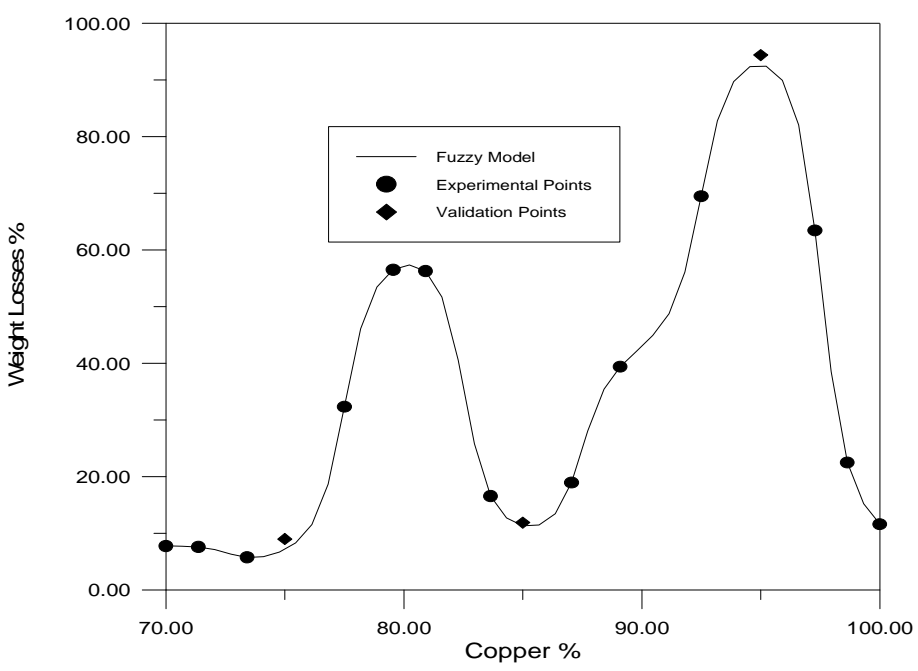

Fig. 5a

$$
\left(P_{W}=12.5 \mathrm{Kgf}, V_{W}=170 \mathrm{~m} / \mathrm{min}\right)
$$




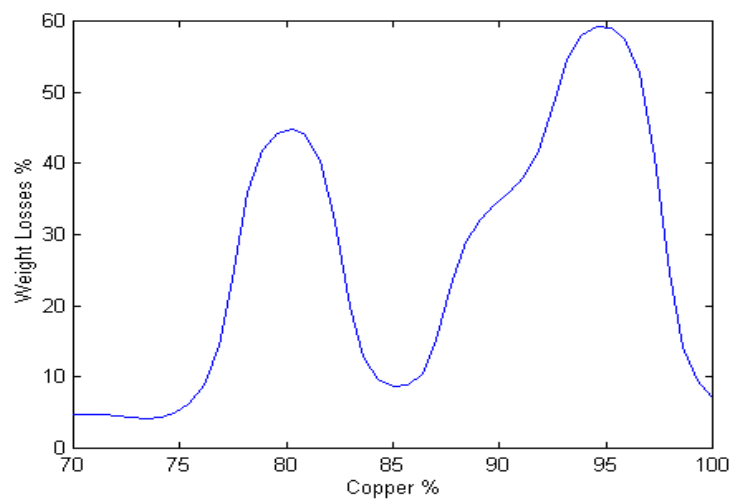

Fig. 5b

$\left(P_{W}=10 \mathrm{Kgf}, V_{W}=127 \mathrm{~m} / \mathrm{min}\right)$

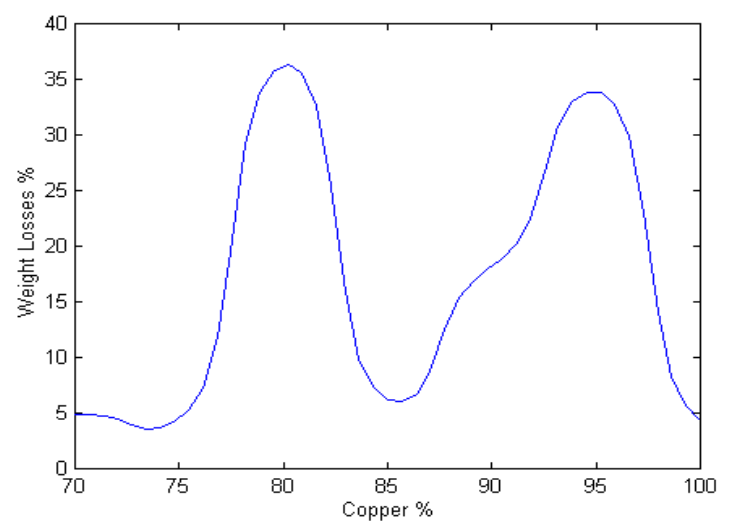

Fig. 5c

$\left(P_{W}=7.5 \mathrm{Kgf}, V_{W}=170 \mathrm{~m} / \mathrm{min}\right)$

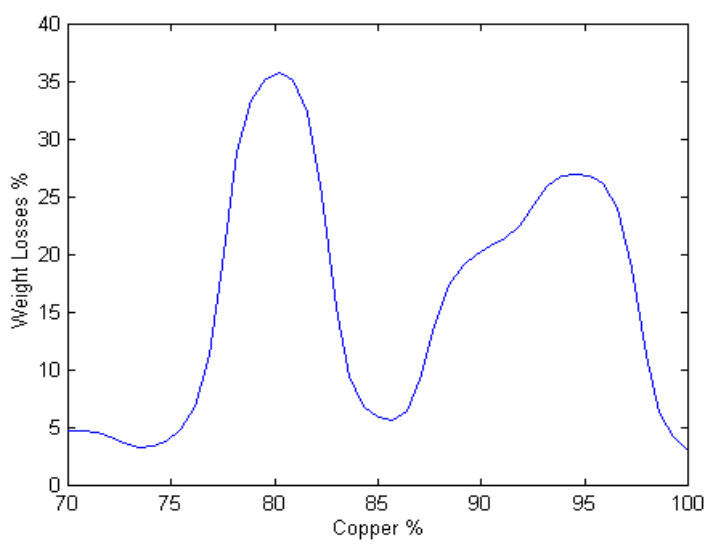

Fig. 5d

$\left(P_{W}=5 \mathrm{Kgf}, V_{W}=70 \mathrm{~m} / \mathrm{min}\right)$

Fig. 5: Copper $\%$ variation versus weight loss for ( $\mathrm{Pb}=5 \%$, and $\mathrm{Sn}=$ rem.) Under Different Velocities and Wear Forces. 


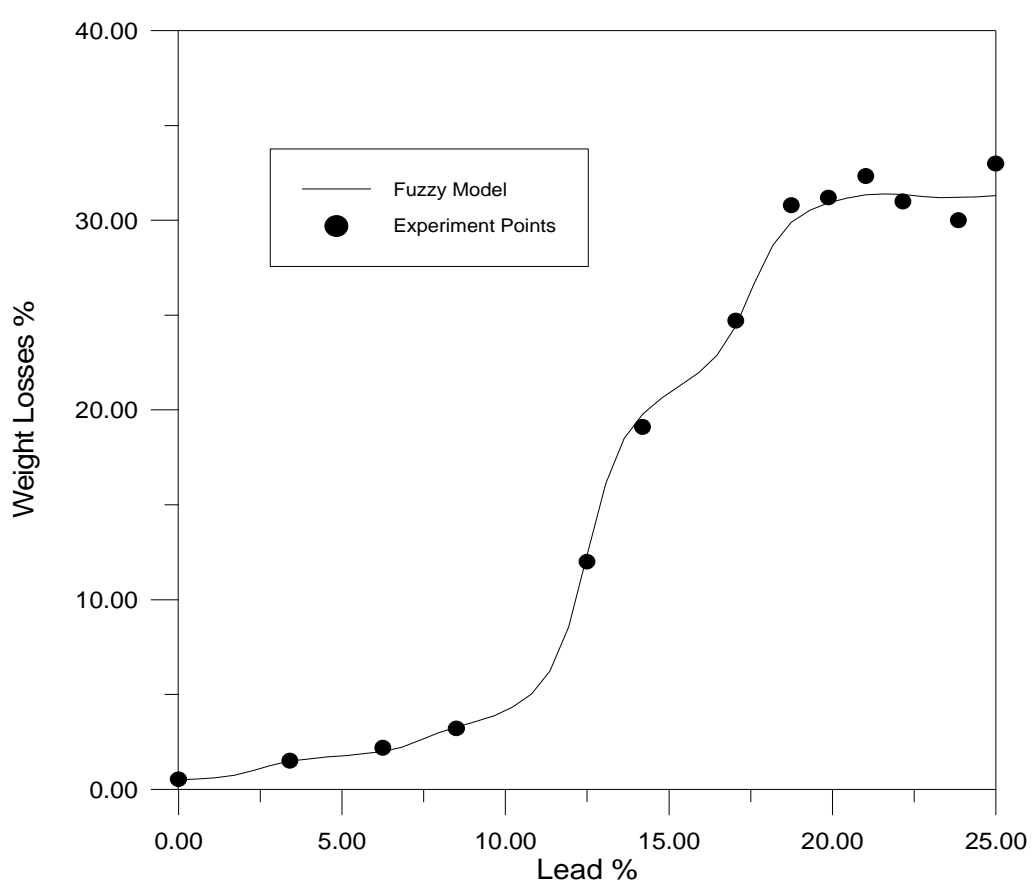

Fig. 6a

$\left(P_{W}=12.5 \mathrm{Kgf}, V_{W}=170 \mathrm{~m} / \mathrm{min}\right)$

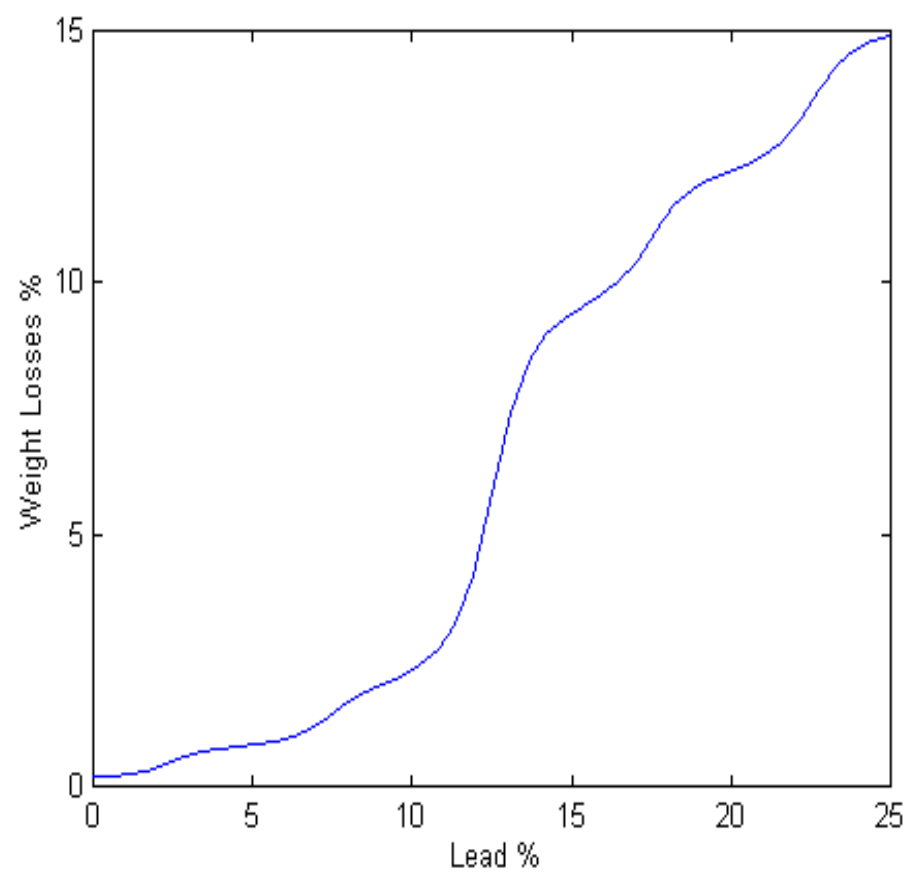

Fig. 6b

( $\left.P_{W}=10 K g f, V_{W}=127 \mathrm{~m} / \mathrm{min}\right)$ 


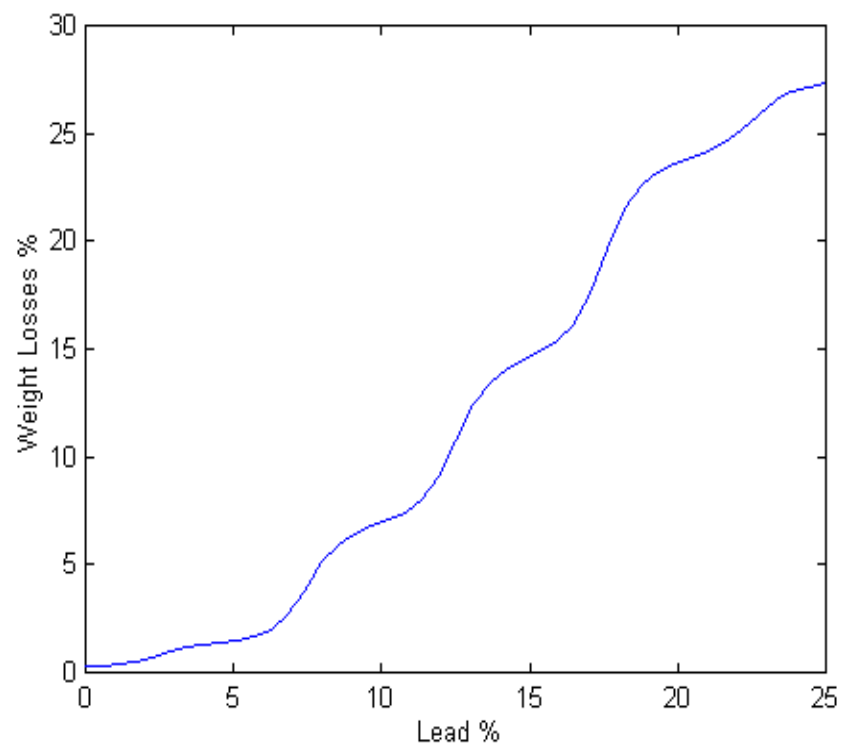

Fig. 6c

$\left(P_{w}=7.5 \mathrm{Kgf}, V_{\mathrm{w}}=170 \mathrm{~m} / \mathrm{min}\right)$

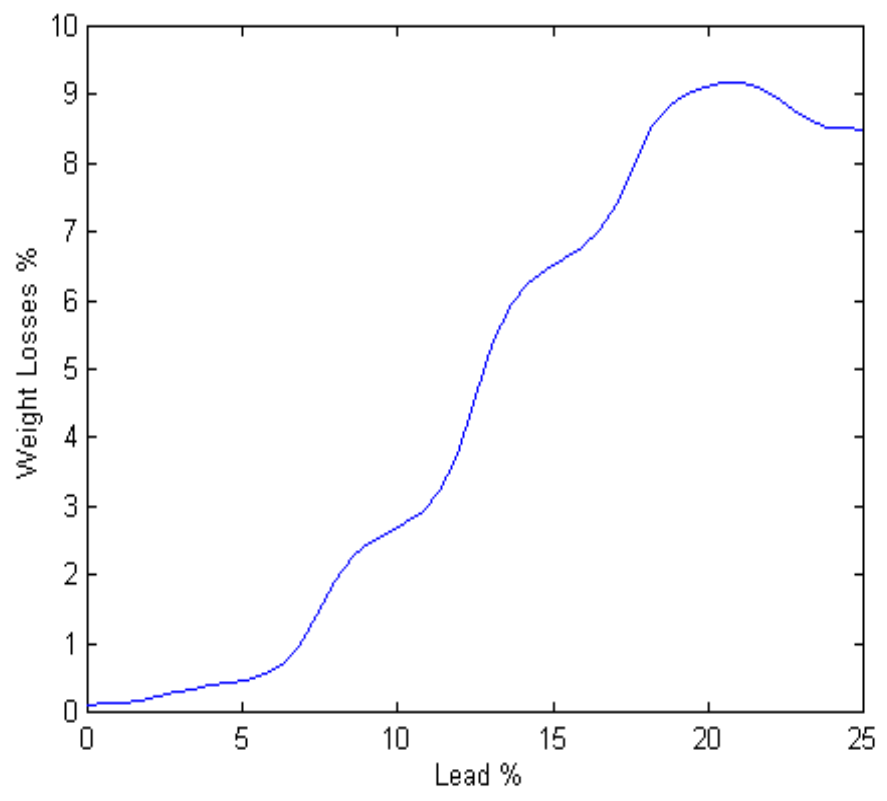

Fig. 6d

$\left(P_{W}=5 \mathrm{Kgf}, V_{W}=70 \mathrm{~m} / \mathrm{min}\right)$

Fig. 6: Lead \% variation versus weight loss for $(\mathrm{Cu}=70 \%$,and $\mathrm{Sn}=$ rem. $)$ Under Different Velocities and Forces. 


\section{Effect of Tin percentage in Copper-Lead-Tin Alloys on Wear}

Figure 7 shows the effect of tin percentage on the considered alloys change with the change in lead percentages for constant copper percentage $(\mathrm{Cu}=70 \%)$. These curves show that weight loss is increased as the tin percentage increased up to $7 \%$, then a rapid decrease in weight loss can be noted. It can be stated from these figures that the weight loss decreases rapidly when the percentage of tin content exceeds $7 \%$. The tin forms a solid solution with a hard constituent develops in cast copper tin alloys because of deviation from true equilibrium as shown in the phase diagram of copper-tin.

\section{Effect of Lead Percentage and Tin Percentage on Weight Loss of Copper- Lead -Tin Alloys}

Figure 6 shows the effect of increasing the lead percentage and decreasing the tin percentage, for constant percentage of copper, $(\mathrm{Cu}=70 \%)$. Figure 7 shows the effect of decreasing the percentage of lead while increasing the percentage of tin, for constant copper percentage $(\mathrm{Cu}=70 \%)$. From these figures it can be noted that as the tin percentage increases and the lead percentage decreases in the alloy, the weight loss will decrease. Figure 8 shows the same effect of tin and lead for the two optimal copper percentages of $75 \%$, and $85 \%$ respectively. From these figures it can be stated that, there is more than one combination of this alloy exhibit high weight loss, also more than one combination with minimum weight loss.

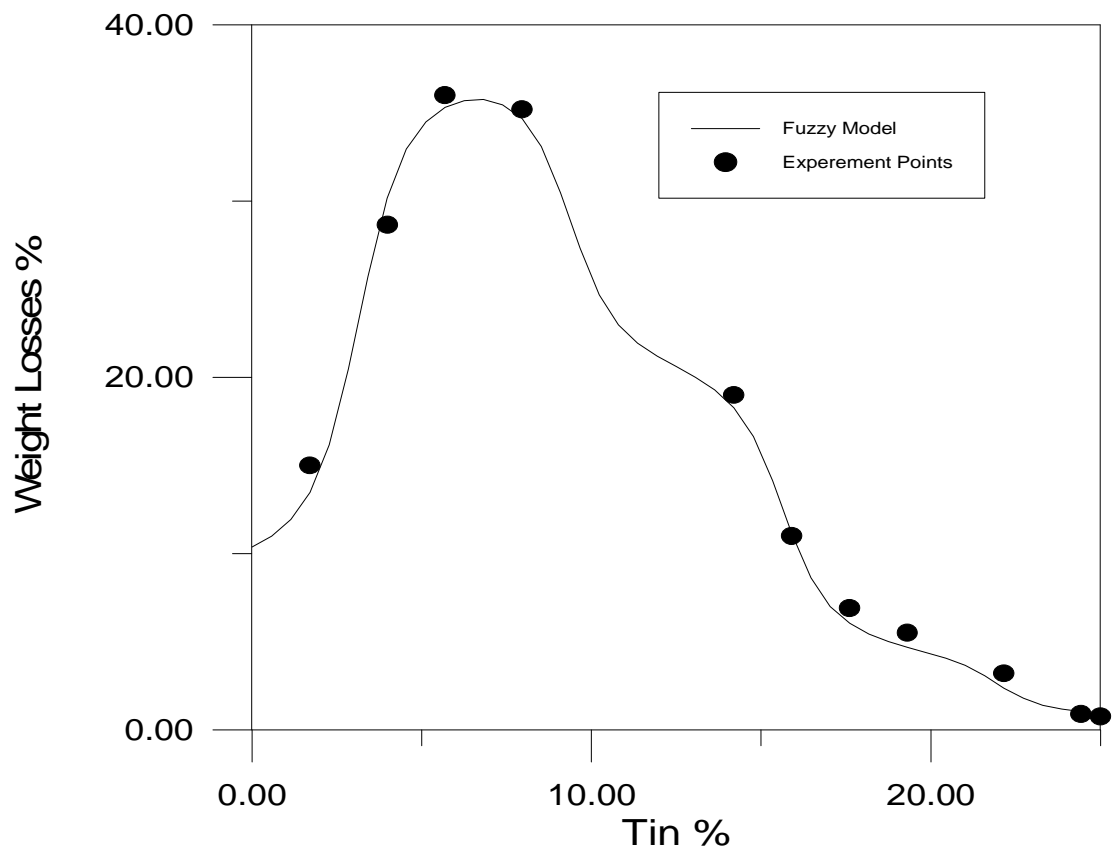

Fig. 7a

$\left(P_{\mathrm{W}}=12.5 \mathrm{Kgf}, \mathrm{V}_{\mathrm{W}}=170 \mathrm{~m} / \mathrm{min}\right)$ 


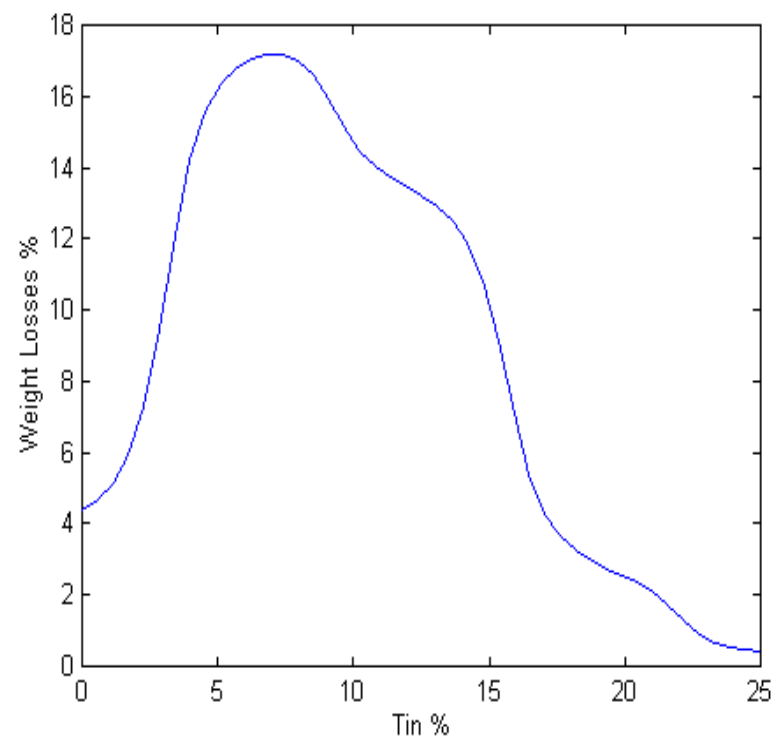

Fig. 7b

$\left(P_{W}=10 \mathrm{Kgf}, V_{\mathrm{W}}=127 \mathrm{~m} / \mathrm{min}\right)$

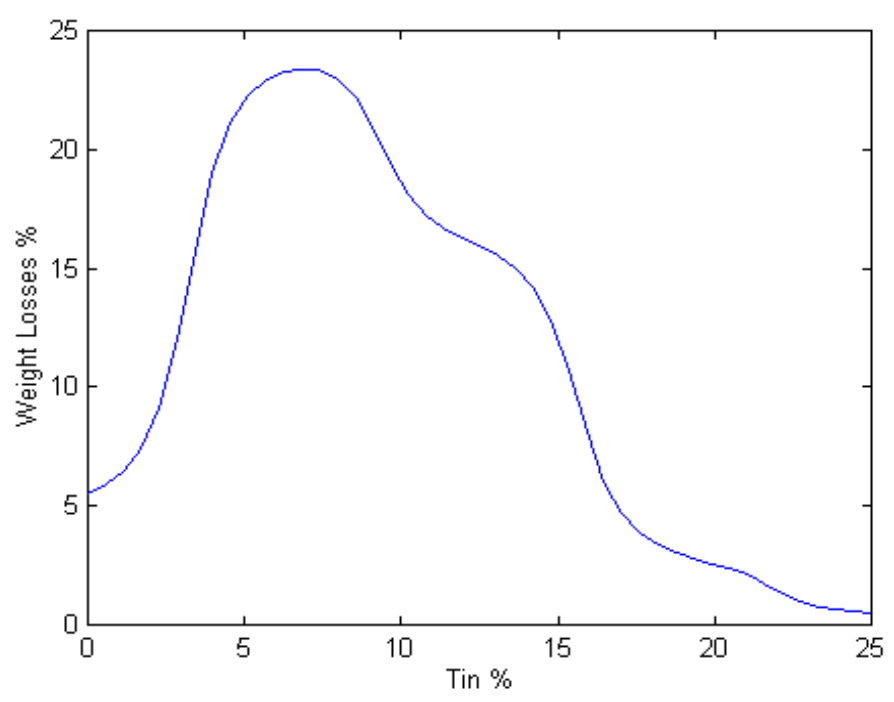

Fig. 7c

$\left(P_{W}=7.5 \mathrm{Kgf}, V_{W}=127 \mathrm{~m} / \mathrm{min}\right)$ 


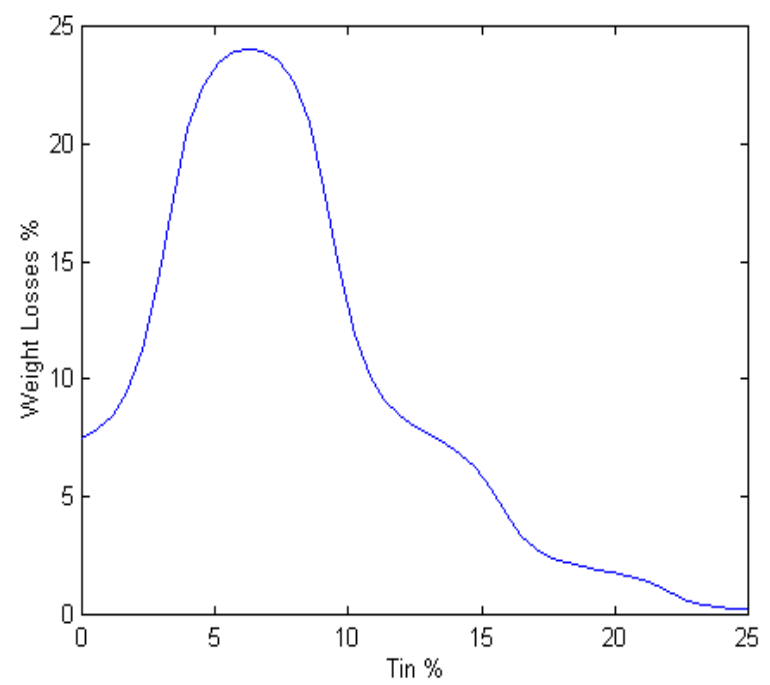

Fig. 7d

$\left(P_{W}=5 \mathrm{Kgf}, V_{W}=70 \mathrm{~m} / \mathrm{min}\right)$

Fig. 7: Tin $\%$ variation versus weight loss for $(\mathrm{Cu}=70 \%$, and $\mathrm{Pb}=$ rem. $)$ at Different Velocities and contact Forces.

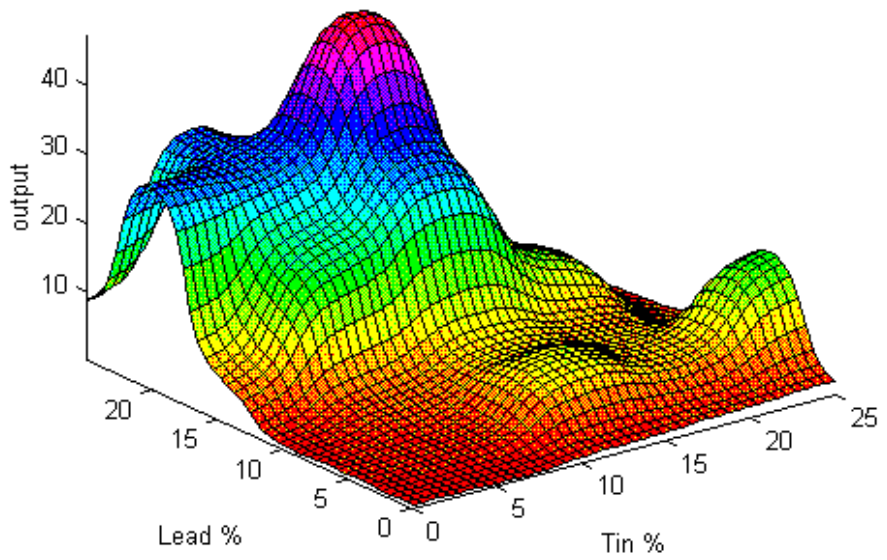

Fig. 8a

$\left(P_{W}=12.5 \mathrm{Kgf}, V_{W}=170 \mathrm{~m} / \mathrm{min}\right)$ for $\mathrm{Cu}=75 \%$. 


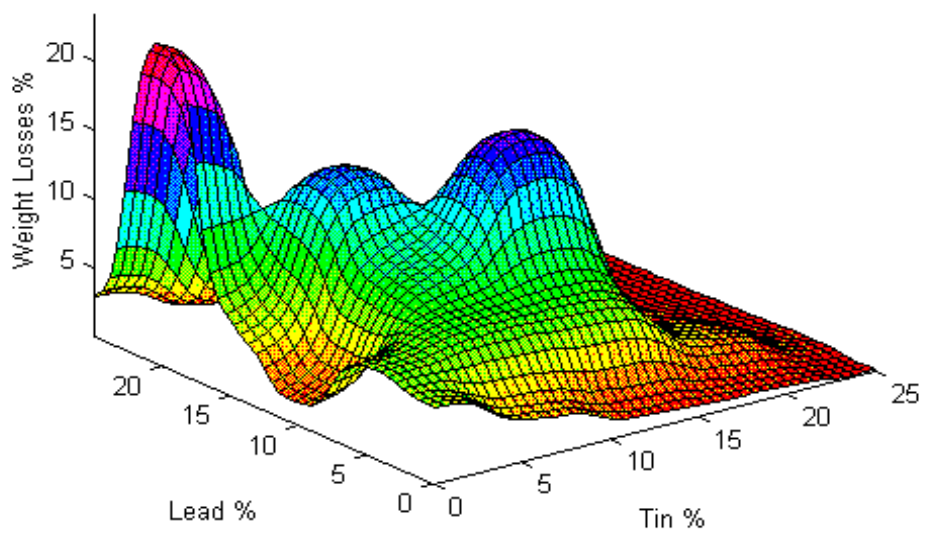

Fig. 8b

$\left(P_{W}=12.5 \mathrm{Kgf}, V_{W}=170 \mathrm{~m} / \mathrm{min}\right.$ ) for $\mathrm{Cu}=85 \%$.

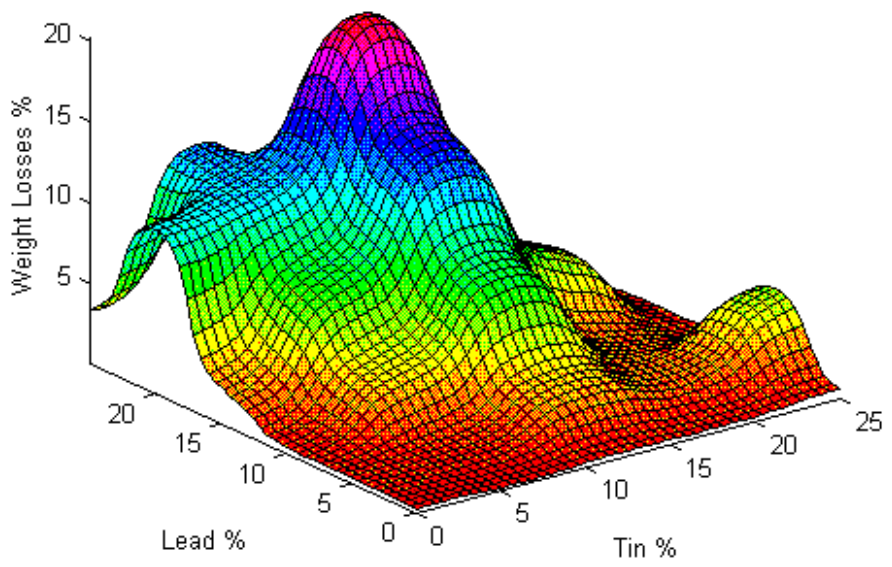

Fig. 8c

( $P_{W}=7.5 \mathrm{Kgf}, V_{W}=94 \mathrm{~m} / \mathrm{min}$ ) for $\mathrm{Cu}=75 \%$. 


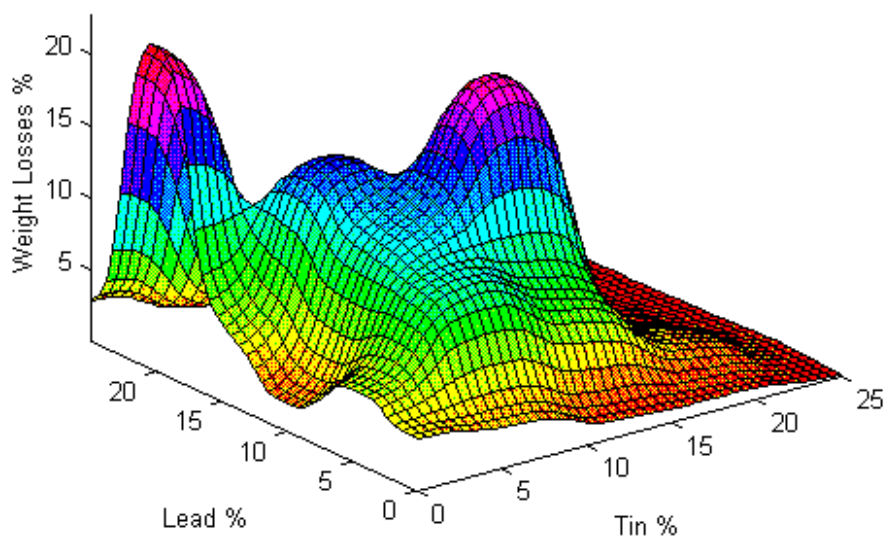

Fig. 8d

( $P_{W}=7.5 \mathrm{Kgf}, V_{W}=94 \mathrm{~m} / \mathrm{min}$ ) for $\mathrm{Cu}=85 \%$.

Fig. 8: Tin \% and lead \% variation versus weight loss at Different Velocities and Wear Forces.

\section{The Optimal Percentages of Lead and Tin in the Copper Alloys With Minimum Weight Loss Under Different Wear Velocities and Forces}

Figure 5 shows that, at $75 \%$, and $85 \% \mathrm{Cu}$ an optimum wear resistance may be achieved. Figures 6 and 7 show that as the tin percentage increases and the lead percentage decreases the wear resistance will increase. Also there are more than one combination of the tin and lead percentage for optimal wear resistance. Figure 8 shows the surface view of lead and tin percentages for the first optimal copper percentage ( $\mathrm{Cu}=75 \%$ ). And also, shows the same thing but for the second optimal copper percentage $(\mathrm{Cu}=85 \%)$. From these figures it can be noted that their are two main alloys with optimal wear resistance, these are $(\mathrm{Sn}=20 \%, \mathrm{~Pb}=5 \%)$ and $(\mathrm{Sn}=10 \%$, $\mathrm{Pb}=5 \%)$.

\section{Effect of Velocity on Weight Loss}

The weight loss with different alloy composition percentages from copper, tin, and lead under different velocities are shown in Fig. 5-8. These curves indicate that weight loss is increased by increasing the velocity for any wear force value. The effect of velocity is to cause on increase in the temperature of sliding interface, which means that the hardness of the metal will decrease, so an increase in the rate of weight loss should be expected. 


\section{Effect of Wear Force with Different Weight Loss}

Again, the increase in wear force will increase the weight loss of all the alloys under consideration as shown in figures 5-8. This is due to the fact that increasing contact force will increase the normal stress at the matting surface and hence an increase of the energy dissipated in overcoming friction which is converted into heat. This heat will raise the interface temperature, which may be high enough to soften and even melt the surface, as well as causes more structural damages.

\section{Experimental Validation of the Fuzzy Model}

The fuzzy model shows that the alloys with the percentages $(\mathrm{Cu}=75 \%, \mathrm{Sn}=$ $20 \%, \mathrm{~Pb}=5 \%)$, and $(\mathrm{Cu}=85 \%, \mathrm{Sn}=10 \%, \mathrm{~Pb}=5 \%)$ were the optimal alloys. Samples from the two optimal alloys were tested experimentally under the same testing conditions. Figure 5, and Fig. 9 show results of the experimental test and the fuzzy model.

It can be noted that similarity between the test and the fuzzy model results. For that, the selected model will be used to represent the behavior of the wear resistance of copper-lead-tin alloys with high accuracy.

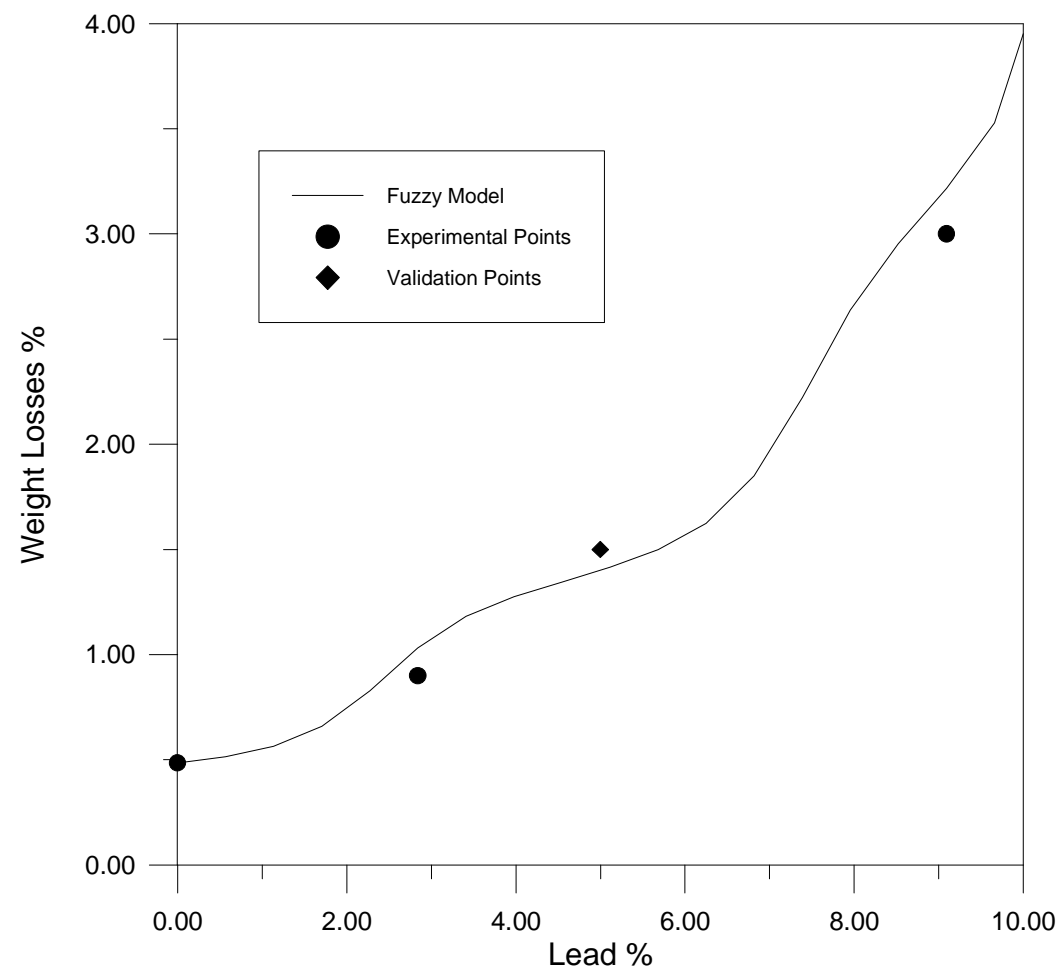

Fig. 9a: Lead \% variation versus weight loss $\left(P_{W}=12.5 \mathrm{Kgf}, V_{W}=170 \mathrm{~m} / \mathrm{min}\right)$ for ( $\mathrm{Sn}=20 \%$ and $\mathrm{Cu}=$ rem.). 


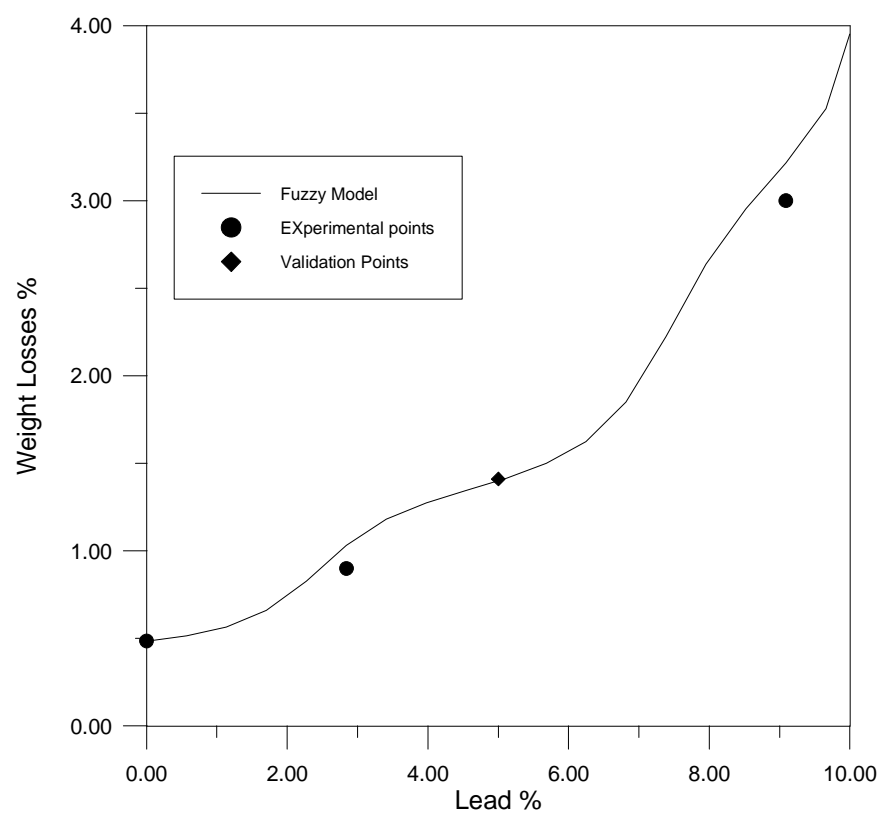

Fig. 9b: Lead \% variation versus weight loss $\left(P_{W}=12.5 \mathrm{Kgf}, V_{W}=170 \mathrm{~m} / \mathrm{min}\right)$ for ( $\mathrm{Sn}=10 \%$ and $\mathrm{Cu}=$ rem.)

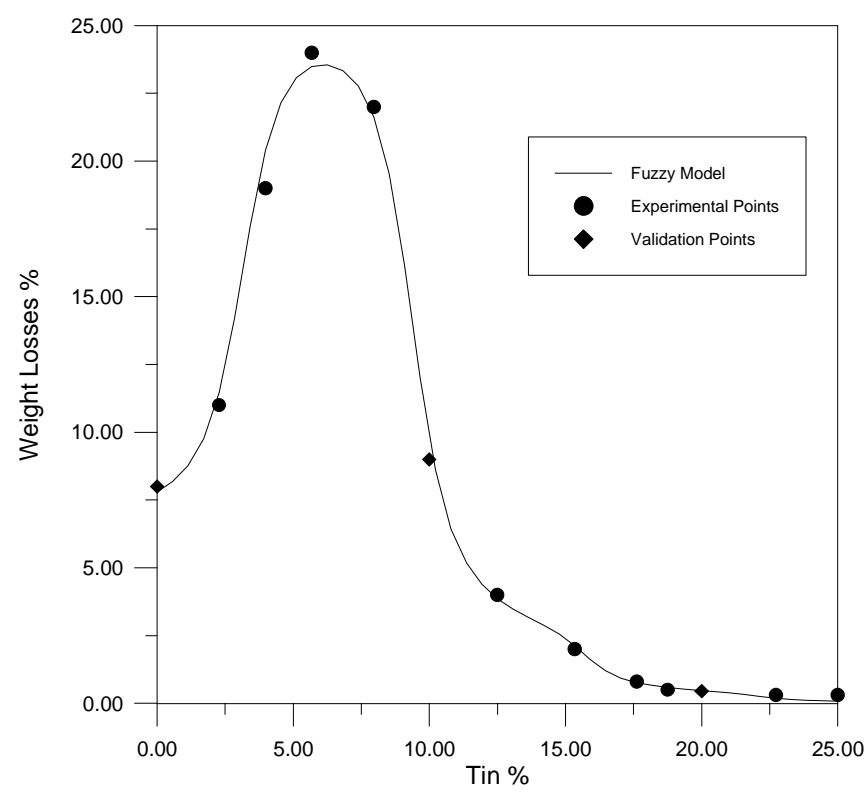

Fig. 9c: Tin \% variation versus weight loss $\left(P_{W}=12.5 \mathrm{Kgf}, V_{W}=170 \mathrm{~m} / \mathrm{min}\right)$ for $(\mathrm{Pb}=5 \%$ and $\mathrm{Cu}=$ rem. $)$

Fig. 9: Lead and Tin \% variation versus weight loss for Different Velocities and Applied Forces. 


\section{CONCLUSIONS}

The following conclusions can be drawn from the present work:

- Wear resistance of copper alloys depends on the composition percentage of the tin, if the tin percentage is less than $7 \%$, then the weight loss will increase and if it is beyond this percentage the weight loss decreases, this is due to the change in the micro-structure of the alloy.

- Increasing the lead composition percentage in the copper alloys will increase the anti- friction of the alloy, and decrease its hardness. Due to the interruption of the discontinuity of $\mathrm{Cu}-\mathrm{Sn}$ alloy matrix, and so decreasing the wear resistance.

- Fuzzy modeling may be successfully used to predict and obtain the output of the wear resistance test, and also, in obtaining the optimal alloy of different copper composition percentages with minimum wear.

- The copper alloys with percentage, $(\mathrm{Cu}=75 \%, \mathrm{~Pb}=5 \%, \mathrm{Sn}=20 \%)$, and ( $\mathrm{Cu}=$ $85 \%, \mathrm{~Pb}=5 \%, \mathrm{Sn}=10 \%)$, are the main alloys with optimal wear resistance from all the alloys compositions studied.

- Increasing both, applied forces and velocities decreases wear resistance of the copper alloys

\section{REFERENCES}

[1] Kalpakjian, Serope, Manufacturing Engineering and Technology, 4rd Edition, Addison-Wesley, Ch.(22,31,32,33), 2001.

[2] Raymond D. Mayer, Wear Testing, ASM Hand Book, Volume 18, Friction, Lubrication and Wear Technology.

[3] George R. Kingsbury, Friction and Wear of Sliding Bearing Materials, Metals Hand Book, Ninth Ed., Volume 3, pp 802- 822.

[4] Milton W. Toaz, Sleeve Bearing Materials, ASM Hand Book, Volume 18, Friction, Lubrication and Wear Technology.

[5] R. D. Mayer, Materials for Sliding Bearings, ASM Hand Book, Volume 18, Friction, Lubrication and Wear Technology.

[6] H. M. Al-Wedyan, Modeling of a Fuzzy System from Numerical Data, M. Sc. Thesis, Jordan University of Science and Technology, 1998.

[7] Fuzzy logic Toolbox, Math Works Inc.

[8] K. N. Abushgair, Wear Resistance Optimization of Copper, Lead, Tin Alloys Under Different Conditions , M. Sc. Thesis, Jordan University of Science and Technology, 1998. 


\section{الحصول على أفضل مقاومة بليان لسبائك النحاس، والرصاص، والقصدير تحت ظروف عمل مختلفة}

\section{دكتور مهندس خليل ناصر أبوشقير}

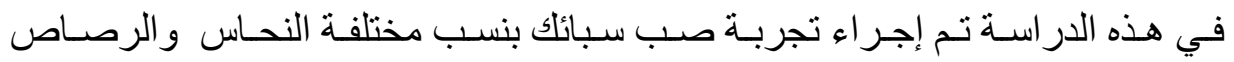

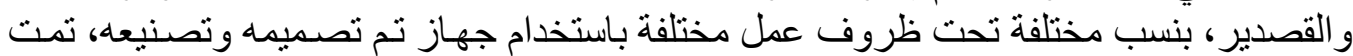

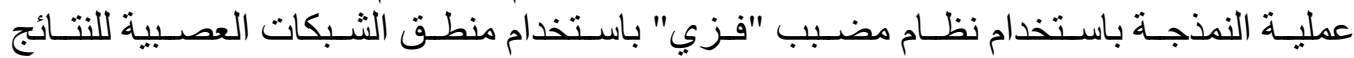

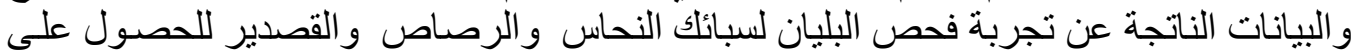

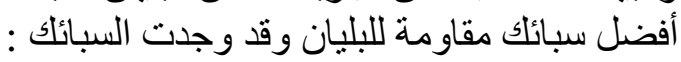

$$
\text { ( } \mathrm{Cu}=85 \%, \mathrm{~Pb}=5 \%, \mathrm{Sn}=10 \%) \quad \text { ） } \quad(\mathrm{Cu}=75 \%, \mathrm{~Pb}=5 \%, \mathrm{Sn}=20 \%)
$$
كافضل سبيكة مقاومة للبليان وقد تم فحص هذة السبيكة مخبريا للتأكد من صحة النظام الفزي. نتيجة لهذا البحث فقد تبين أنه كلما زادت نسبة الرصاص في في السبيكة كلمـا قلت مقاومـة البليان، وكلماز زادت نسبة القصدير عن 7 \% كلماز زادت مقاومة البليان لهذه السبيكة نتيجة لتغير التهات التركيب الداخلي لها. 